
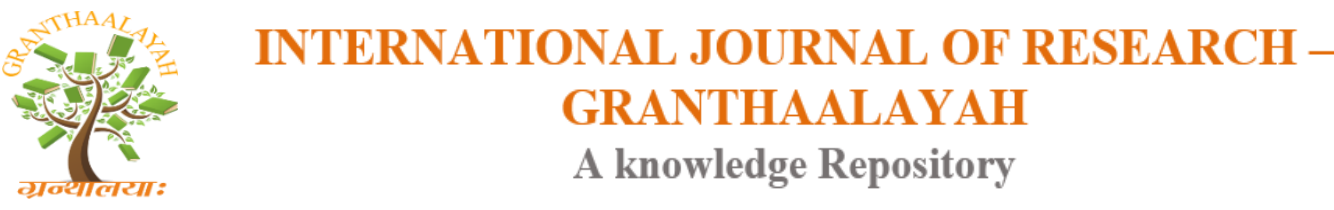

Social

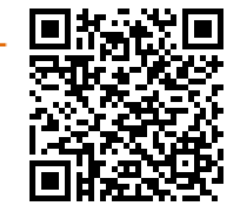

\title{
A STUDY OF RELATIONSHIP BETWEEN INTERNET USAGE AND SELF-REGULATED LEARNING OF UNDERGRADUATES
}

\author{
Dr. Meena Prakash Kute ${ }^{* 1}$, SadhanaPote-Palsamkar ${ }^{2}$ \\ ${ }^{* 1}$ Principal, Research Guide, PVDT College of Education for Women, SNDT Women's \\ University, Mumbai-20, India \\ ${ }^{2}$ Research Scholar, Department of Education, SNDT Women's University, Mumbai-20, India
}

DOI: https://doi.org/10.29121/granthaalayah.v5.i4(SE).2017.1947

\begin{abstract}
The present paper is based on the descriptive correlational research study which aimed to study the relationship between internet usage and self-regulated learning of undergraduates. The survey method was employed to collect the data from commerce, science and arts undergraduates of Mumbai University. The findings of present study showed that, there is significant relationship between internet usage and self-regulated learning of undergraduates. The relationship was found to be positive and negligible.
\end{abstract}

Keywords: Internet Usage; Self-Regulated Learning; Undergraduates.

Cite This Article: Dr. Meena Prakash Kute, and SadhanaPote-Palsamkar. (2017). "A STUDY OF RELATIONSHIP BETWEEN INTERNET USAGE AND SELF-REGULATED LEARNING OF UNDERGRADUATES." International Journal of Research - Granthaalayah, 5(4)SE, 32-40. https://doi.org/10.29121/granthaalayah.v5.i4(SE).2017.1947.

\section{Introduction}

The use of internet in education is increasing day-by-day. Internet provides infinite and easily accessible learning resources as well as fast communication. Internet is becoming more available in education as a learning tool, so internet users need certain competencies in order to make effective use of it. Today's digital generation is using internet for learning purpose as well as for leisure time activities. Therefore, it is expected that they develop SRL in using technology specially internet for learning purposes. Self-regulated learning plays important role in academics of learners, also self-regulation plays important role in internet use.

\section{Self-Regulated Learning}

Self-regulated learning has been studied deeply and different people, which explains the process of self-regulated learning, have proposed many models. SRL model formulated by Pintrich 
comprises four phases of self-regulation and, for each phase, four possible areas for selfregulation. This model specifies the possible range of activities; it does not necessitate them.

\section{Phase I - Forethought, planning, and activation}

Cognitions that can be self-regulated during this phase include goals, prior content knowledge, and metacognitive knowledge. Goals involve setting and modifying task-specific goals that serve as criteria against which to gauge progress. Activation of relevant content knowledge may occur without conscious awareness, but self-regulated learners often activate knowledge in a planned way through prompting and self-questioning.

\section{Phase II - Monitoring}

The second phase is monitoring, or attention and awareness of one's actions and their outcomes.

\section{Phase III - Control}

During this phase learners attempt to control their cognitions, motivation, behaviors, and contextual factors based on their monitoring with the goal to enhance learning.

\section{Phase IV - Reaction and reflection}

Learners' reactions and reflections include judgments, attributions, and self-evaluations of performance.

Corno and Mandinach developed a self-regulation model in 1983, which explains the interactions of processes, and strategies as individuals cognitively engage in instructional tasks. Donna Rogers (2001) tried to explore the applicability of Corno and Mandinach's model to Internet searching. She explained that the components of the Corno and Mandinach model describe and predict the behaviors of internet users who are engaged in learning.

The Corno and Mandinach (1983) model of self-regulated learning describes a cyclic path through which students engage in academic tasks, motivated by a combination of initial and sustaining interest. It has two processes, acquisition and transformation, with five strategies.

The Corno and Mandinach (1983) model of self-regulated learning identifies two processes, acquisition and transformation, with five embedded strategies within those processes. Their model depicts a cyclic path through which students engage in academic tasks, motivated by a combination of initial and sustaining interest. The relative use of the processes of acquisition and transformation defines four forms of cognitive engagement, with those individuals who use high levels of both acquisition and transformation being labeled self-regulated learners.

\section{Self-Regulation Components of CornoMandinach Model}

\begin{tabular}{|c|c|c|}
\hline \multirow[t]{2}{*}{ ACQUISITION } & - Alertness & $\begin{array}{l}\text { Receiving incoming stimuli Tracking and } \\
\text { gathering information }\end{array}$ \\
\hline & - Monitoring & $\begin{array}{l}\text { Continuous tracking of stimuli and } \\
\text { transformations } \\
\text { - Researching } \\
\text { - Planning } \\
\text { - Self-checking }\end{array}$ \\
\hline
\end{tabular}




\begin{tabular}{|l|cl|l|}
\hline TRANSFORMATION & $\bullet$ Selectivity & $\begin{array}{l}\text { Discriminating among stimuli } \\
\text { Distinguishing relevant from irrelevant } \\
\text { information }\end{array}$ \\
\cline { 2 - 4 } & $\bullet$ Connecting & $\begin{array}{l}\text { Searching for familiar knowledge } \\
\text { Linking familiar knowledge to incoming } \\
\text { information }\end{array}$ \\
\cline { 2 - 4 } & $\bullet$ Planning & $\begin{array}{l}\text { Organizing a task approach sequence or } \\
\text { performance routine }\end{array}$ \\
\hline
\end{tabular}

According the Corno and Mandinach (1983) the strategies of acquisition "bound and control the transformation processes of selectivity, connecting new information to that available in memory, and planning use of specific performance routines. The acquisition processes can be seen as metacognitive to the extent that they regulate the transformation processes'.

Alertness is indicated by selecting a search engine and specifying keywords or category entries, as well as through advanced strategies such as the use of multiple screens during acquisition stages. Selecting is detected when students make notes, highlight important points, or determine the relevancy or irrelevancy of the information on the screen. Relevancy is related to the connecting strategy in which student link familiar knowledge or associations with incoming knowledge.

Connecting include adding information to an outline provided in the task description and developing notes in a hierarchical arrangement or rearrangement of existing information.

Planning is associated with organizing and prioritizing subtasks and reacting to feedback. In the transformation stage, students evaluate data received to build understandings from relevant information to make decisions about next steps. Monitoring is much like planning, except that the focus is on the goals of the entire task rather than sub-goals.

\section{Internet Usage}

India is second country in world after China with large number of internet users and the number of users is still increasing rapidly. The internet has been considered as the most powerful technology, which many applications namely, email, search engines, blogs, social networking sites, instant messaging, online learning resources, chat room and many more. Each application is useful for learning in some or other way.

Today, the use of internet in education has increased. It is an educational tool with various applications. It helps us to communicate, gather information, and provides easily accessible learning resources. It is assumed that students are using internet more for various purposes including educational as well as recreational. They are spending more time on internet. So, the impact of internet on the daily life of students has been significantly observed. Researches have proved both negative and positive effect of internet use on students. 


\section{Review of Researches}

Review of literature and researches is important step towards finding the research gap and deciding the research topic. Researcher went through many researches as well as literature related to internet use and self-regulated learning.

\subsection{Researches on Internet Usage}

Asdaque, M.; Khan, M.; Rizvi, S. (2010), Tella, A. (2007), Biktimirov, E.; Klassen, K. (2008), Chen, S. and Fu, Y. (2009) examined the relationship between internet use and academic achievement of students. Results showed the significant negative relationship between two variables.

Englandera, F.; Terregrossab, R. and Wangc, Z. (2010) conducted the study, the findings of which showed a negative and statistically significant relationship between students' hours per week of Internet use and the student's exam performance in an introductory micro-economics course and indicated negative and significant impact of Internet hours on grade performance.

Rouis, S.; Limayem, M.; Salehi-Sangari, E. (2011) analyzed the effects of Facebook usage by undergraduate students at Luleå University of Technology in Sweden. Results indicated an extensive use of Facebook by students with extraverted personalities leading to poor academic performance. However, students who are more self-regulated more effectively control their presence on these platforms. Trust in people does not affect their presence and interaction on this platform. Yet students' cognitive absorption with Facebook is only regulated by their self-control and their personality traits, which determines how much time they spend on Facebook. Multitasking skills moderate the effect of cognitive absorption on academic achievement, but they do not impede the time spent, frequency, or nature of use or their effect on academic results.

Sung, H.; Yang, K. (2009) conducted correlational study, which inferred that the student's selfregulation negatively correlated with their internet browsing and positively correlated with their academic achievement, and their non-academic internet browsing negatively correlated with their academic achievement. No statistically significant correlation between internet use and academic achievement, self- regulation and academic achievement and also self-regulation and internet use was found.

Wanajak, K. (2011) conducted research to understand internet use and its impact on secondary school students in chiangmai, Thailand. It was concluded that the amount of time spent on the Internet is related to gender, having Internet access at home, using the Internet alone and private school attendance. IA is directly correlated with the amount of time spent on the Internet per week, with addictive users spending on average 29 hours per week on the Internet.

\subsection{Researches on Self-Regulated Learning}

Cobb, R. (2003),Kosnin, A. (2007) concluded in their research study that there exists a significant positive relationships between SRL and academic achievement. 
According to Cekolin, C. (2001), prompting appeared to be a critical component of selfregulated learning strategy instruction with all groups. Selected groups of study showed greater increases in both academic achievement and self-regulated learning strategy use when prompting was a component of self-regulated learning strategy instruction. Students who demonstrated either below average self-regulated learning strategy skills or lower GPAs showed the greatest gain from prompting plus instruction. Gender differences were demonstrated, with females showing greater self-regulated learning strategy use compared to males. The findings from this study emphasized the importance of self-regulated learning strategy instruction, especially for middle school students.

Pintrich, P. and De Groot, E. (1990) proved the self-efficacy and intrinsic value were positively related to cognitive engagement and performance. Regression analyses revealed that, depending on the outcome measure, self-regulation, self-efficacy, and test anxiety emerged as the best predictors of performance. Intrinsic value did not have a direct influence on performance but was strongly related to self-regulation and cognitive strategy use, regardless of prior achievement level.

Rogers, D.; Swan, K. (2004) demonstrated that the model of self-regulated learning developed by Corno and Mandinach relative to traditional classroom activities could be applied to Internet searching behaviors. The study also found that not all Internet searchers are equal; thus, researcher suggestedthat students need to be helped to become better at it.

Rogers, D.; Swan, K. (2004) demonstrated that the model of self-regulated learning developed by Corno and Mandinach relative to traditional classroom activities could be applied to Internet searching behaviors. The study also found that not all Internet searchers are equal; thus, researcher suggestedthat students need to be helped to become better at it.

Samruayruen, B. (2013) conducted a research to identify the existing level of selfregulatedlearning (SRL) among Thai online learners, and found that Thai online learners have high levels of SRL characteristics.

Sung, H.; Yang, K. (2009) conducted correlational study, which inferred that the student's selfregulation negatively correlated with their internet browsing and positively correlated with their academic achievement, and their non-academic internet browsing negatively correlated with their academic achievement. No statistically significant correlation between internet use and academic achievement, self- regulation and academic achievement and also self-regulation and internet use was found.

Uzun, A.; Unal, U.; Yamac, A. (2013) examined pre-service teacher's academic achievements in terms of different variables such as online self-regulated learning skills and attitudes towards distance education. The results showed a significant positive and low correlation between attitudes towards distance education and self-regulated learning skills. According researchers the highest level of self-regulated learning skills are associated with the highest level of attitudes toward online distance education. 
Zulkiply, N.; Kabit, M.; Ghani, K. (2008), Schleifer, L. and Dull, R. (2009), Sperling, R.; Richmond, A.; Ramsay, C.; Klapp, M. (2012) explored the association between metacognition and student performance and success. Overall, the findings revealed a significant positive relationship between student's academic performance and metacognition.

Internet use of students has been studied more extensively with respect to variables like demographic information, study habits, academic achievement, attitude and other factors. In addition, many studies have explored how the Internet can be used in meaningful ways in education and negative consequences that can arise from excessive Internet usage have been examined. However, researcher could find very few researches, which will explore relationship between internet use and self-regulated learning of students. The present survey is, therefore, an attempt to assess the relationship between self-regulated learning and internet usage with special reference to the undergraduates of Mumbai University from greater Mumbai region.

\section{Statement of the Problem}

A Study of Relationship between Internet Usage and Self-Regulated Learning of Undergraduates.

\section{Operational Definitions of Variables}

Internet usage: Internet usage can be operationally defined as, use of Internet by undergraduates for educational purpose including notes making, project work/assignment, doubt clearing, acquiring information about any subject, enriching general knowledge and communicating with teachers, experts and peers for learning purpose; which will be measured by using rating scale.

Self-regulated learning: Self-regulated learning is an active, constructive process whereby learners set goals for their learning and then attempt to monitor, regulate, and control their cognition, motivation, and behavior, guided and constrained by their goals and the contextual features in the environment.

Undergraduates: Undergraduates can be operationally defined as students who have passed second year of graduation in arts, science or commerce stream and admitted to third year of graduation.

\section{Objectives of the Research}

The research had the following objectives for exploration

1) To study the internet usage of undergraduates.

2) To study the self-regulated learning of undergraduates.

3) To study the relationship between internet usage and self-regulated learning of undergraduates.

\section{Hypothesis of the Study}

Ho1: There is no significant relationship between Internet use and self-regulated learning of undergraduates 


\section{Research Methodology}

This descriptive correlational research was concerned with internet usage and self-regulated learning of undergraduates. Survey method was employed to collect data. The present study is based on the information provided by 1540 students of colleges from greater Mumbai of Mumbai University. To collect the data, internet usage questionnaire was designed, keeping in view the objectives of the study. Pre- pilot and pilot studies were carried out to find the validity and reliability of tool. The maximum score for internet usage questionnaire is 168. Also self-report Questionnaire MSLQ (the Motivated Strategies for Learning Questionnaire developed by Pintrich and DeGroot (1990) was used. The actual data was collected from randomly selected colleges from Mumbai and Mumbai suburban region. The stratified random sampling techniques were used to select the sample of 1540 undergraduates from selected colleges. Stratification was done in the case of faculty.

The present study undertook greater Mumbai. Colleges of Mumbai University from greater Mumbai were selected. The present study was confined to 1540 undergraduates of arts, science and commerce. The study is limited to internet usage of third year undergraduates of Mumbai University.

Out of 2000 students only 1540 questionnaires were selected by researcher. Some students didn't return the questionnaire and few questionnaires were rejected by researcher as they were incomplete. The investigator analyzed the data with the help of descriptive and inferential statistical measures.

\section{Data Analysis and Findings}

The data were described using statistical techniques like mean, median, mode, SD, skewness and kurtosis. The fiduciary limits of the mean and SD was found out at 0.95 level and 0.99 levels. This was done in order to establish the normality of the distributions and to estimate the population parameters respectively.

Table 1: Descriptive Analysis of the Data

\begin{tabular}{|c|c|c|c|c|c|c|c|}
\hline VARIABLES & SUM & Mean & Median & Mode & kurtosis & Skewness & SD \\
\hline Internet Usage & 104586 & 67.91299 & 66 & 69 & -0.14862 & 0.444173 & 19.00802 \\
\hline $\begin{array}{c}\text { Self-Regulated } \\
\text { Learning }\end{array}$ & 324133 & 210.476 & 212 & 224 & -0.13329 & -0.23479 & 34.0809 \\
\hline
\end{tabular}

The mean, median and mode of Internet usage for the total sample are 67.91104, 66 and 69.

The skewness is positive, which is 0.444257 . The kurtosis is -0.14063 and hence distribution is said to be platykurtic.

The mean, median and mode of self-regulated learning for the total sample are 210.476,212 and 224. The skewness is negative, which is -0.23479. The kurtosis is -0.13329 and hence distribution is said to be platykurtic. 
Table 2: Significance of ' $\mathrm{R}$ ' For Internet Usage and Self-Regulated Learning

\begin{tabular}{|l|l|l|l|}
\hline Sample size & Df & R & l.o.s. \\
\hline 1540 & 1538 & 0.09 & 0.01 \\
\hline
\end{tabular}

The obtained " $r$ " is greater than the tabulated " $r$ " that is 0.081 . Hence, null hypothesis is rejected at 0.01 level. So there is significant relationship between internet usage and self-regulated learning.

Interpretation of ' $\mathbf{r}$ ': The coefficient of correlation between internet usage and self-regulated learning is 0.09 , which is positive, negligible in magnitude and significant at 0.01 level. It was found that, there exists a significant relationship between Internet Usage and Self-Regulated Learning of third year undergraduates.

\section{Conclusion}

From the findings, it is concluded that the mean, median, mode are approximately equal for both internet usage and self-regulated learning. The distributions are slightly negatively skewed in some cases and slightly deviate from being mesokurtic. However, they may be termed as normal in nature. There is a significant relationship between Internet Usage and Self-Regulated Learning of third year undergraduates. The relationship was found to be positive and negligible. This infers that self-regulated learners have high internet usage. The Corno- Mandinach model explains how internet use and self-regulated learning strategies are interrelated. Each step of internet usage is nothing but self-regulated learning strategy. Self-regulated learners can potentially monitor, control, and regulate certain aspects of their own cognition, motivation, and behavior as well as some features of their environments. Therefore they also control their internet usage and make it productive.

Most of the youngsters spend a substantial amount of time on internet every day. So this research is helpful for educators, teachers and parents to understand the use of internet applications by undergraduates and its relationship with self-regulated learning. Today's digital generation is using internet for learning purpose as well as for leisure time activities. Therefore, it is necessary that they develop SRL in using internet for learning purpose, which is positively related to it.

\section{References}

[1] Anderson, K.J. Internet use among college students: An exploratory study.

[2] Banerjee, I. (2007). Internet and Governance in Asia. Singapore: Booksmith.

[3] Comer, D.E. (2003). The internet: 3rd edition. New Delhi: Prentice-Hall of India.

[4] Golden, S. A. R. (2017). Attitude of Students and Teachers towards E- Learning - An Analysis. Recent Research in Social Science \& Humanities, 1, 5-10.

[5] Golden, S. A. R. (2017). Recent Research In Social Science \& Humanities.

[6] Green, L. (2002). Communication and society. New Delhi: Sage Publication.

[7] Kaul, Lokesh (1997). Methodology of Educational Research. New Delhi: Vikas Publishing House Pvt. Ltd.

[8] Kothari, C.R. (2010). Research Methodology: Methods and Techniques. New Delhi: New Age International. 
[9] Chen, S.; Fu, Y. (2009). Internet use and academic achievement: gender differences in early adolescence. Adolescence, 44(176), 797-812. Retrieved on from http://search.proquest.com/docview/195938430?accountid=28682 May 22, 2013

[10] Gencer, S. L.; \&Koc, M. (2012). Internet Abuse among Teenagers and Its Relations to Internet Usage Patterns and Demographics. Educational Technology \& Society, 15 (2), 25-36. Retrieved from http://www.ifets.info/journals/15_2/4.pdf on March 15, 2013.

[11] Nair, L. (1999). Internet use by children. Unpublished M. LiSc. Dissertation, Mumbai: SNDT Women's University.

[12] Rogers, D. M. (2001). An investigation of components in corno and mandinach's self-regulated learning model applied to internet navigation. (Order No. 3012362, State University of New York at Albany). ProQuest Dissertations and Theses, 233-233 p. Retrieved from http://search.proquest.com/docview/231010681?accountid=28682.on June 22, 2014.

[13] Rouis, S.; Limayem, M.; Salehi-Sangari, E. (2011). Impact of Facebook Usage on Students' Academic Achievement: Role of self-regulation and trust. Electronic Journal of Research in Educational Psychology, 9(3), 961-994. Retrieved from http://www.investigacionpsicopedagogica.com/revista/articulos/25/english/Art_25_620.pdf on August 25, 2013.

[14] Ruzgar, N. S. (2005). A research on the purpose of Internet usage and learning via Internet. The Turkish Online Journal of Educational Technology, 4(4), 27-32.

[15] Samruayruen, B., Enriquez, J., Natakuatoong, O., Samruayruen, K. (2013). Self-Regulated Learning: A Key of a Successful Learner in Online Learning Environments in Thailand. Journal of Educational Computing Research. 48(1), 45-69. Retrieved on 6/12/2015http://journals.sagepub.com/doi/abs/10.2190/EC.48.1.c

[16] Sancheti, A. (2012). Impact of internet use on youth. Unpublished M. HSc. Dissertation, Mumbai: SNDT Women's University.

[17] Shah, P. (1999). Internet use by faculty members in research institutes in Mumbai. Unpublished M. LiSc. Dissertation, Mumbai: SNDT Women's University.

[18] Tella, A, Tella, A, Ayeni, O \&Omoba, RO. 2007. Self-efficacy and use of electronic information as predictors of academic performance. Electronic Journal of Academic and Special Librarianship $8(2): 18-21$.

[19] Thomson, S.J. (1996). Internet Connectivity: Addiction and Dependency Study. Retrieved from http://mediainformatics.biz/iads/ on October 21, 2013.

[20] Wanajak, K. (2011).Internet use and its impact on secondary school students in Chiang Mai, Thailand. Retrieved on 20/5/14 at14.18 p.m. http://ro.ecu.edu.au/theses/394. 